\title{
THE ECOLOGY OF BIPOLAR DISORDER: THE IMPORTANCE OF SLEEP
}

\author{
By: Mary Grace Umlauf and Mona Shattell
}

Umlauf, M., \& Shattell, M. (2005). The ecology of bipolar disorder: The importance of sleep. Issues in Mental Health Nursing, 26(7), 699-720.

Made available courtesy of Taylor and Francis:

http://www.informaworld.com/smpp/title $\sim$ content=t713669522

\section{***Note: Figures may be missing from this format of the document}

\begin{abstract}
:
Although much of the emphasis in treating Bipolar Disorder patients is on pharmacotherapy, sleep loss is an important trigger for mania and plays an important role in the condition. The purpose of this paper is to fully explore the chronobiological, environmental, social, and genetic factors that contribute to the sleep disruption that is characteristic of mania and bipolar disorder. This review is important because sleep, chronobiology, and genetics are under-emphasized content areas in nursing education. As a result, many practicing nurses are unaware of the importance of sleep for mental health or what to teach patients to improve both the quality of their sleep and the management of their condition.
\end{abstract}

\section{Article:}

Bipolar disorder affects over 2.3 million adults in the United States every year (National Institute of Mental Health, 2000). Bipolar disorder is characterized by extremes of mood including both depression and mania. The most distinguishing symptom of bipolar disorder is the manic episode, which is essentially an extended period, usually 24 hours or more, of persistent activity without sleep. A manic episode is "defined by a distinct period during which there is an abnormally and persistently elevated, expansive, or irritable mood" (American Psychiatric Association, 1994, p. 328). Additional symptoms of mania include: "inflated self-esteem or grandiosity, decreased need for sleep (e.g., feels rested after only 3 hours of sleep), more talkative than usual or pressure to keep talking, flight of ideas or subjective experience that thoughts are racing, distractibility, increase in goal-directed activity or psychomotor agitation, and excessive involvement in pleasurable activities that have a high potential for painful consequences (e.g., engaging in unrestrained buying sprees, sexual indiscretions)" (p. 332).

Much of the focus in the nursing literature on bipolar disorder has emphasized medication management (Lewis, 2004; Shattell \& Keltner, 2004; Tugrul, 2003). An important aspect of bipolar disorder and mania that has received little attention in the literature is sleep. The American Psychiatric Association (2002) does, however, include in its revised practice guidelines for the treatment of bipolar disorder a discussion of the importance of regular sleep patterns. Only a handful of studies, however, have examined sleep problems in persons with bipolar disorder (Boivin, 2000; Leibenluft, 1996; Leibenluft \& Suppes, 1999). In a review of prodromal symptoms of bipolar disorder (Jackson, Cavanagh, \& Scott, 2003), the most robust early symptom of mania was sleep disturbance (median prevalence $77 \%$ ). In addition to these findings, normalizing and structuring a regular pattern of sleep and daytime activities may 
lengthen time between exacerbations of the illness (Frank, Swartz, \& Kupfer, 2000; Frank et al., 1997; Miklowitz et al., 2003). In light of these findings, it is important for psychiatric/mental health nurses and other mental health care providers to be fully apprised of the importance of sleep for patients with bipolar disorder.

\section{DECONSTRUCTING THE ECOLOGY OF BIPOLAR DISORDER}

Although much of the emphasis on treatment of bipolar disorder is based on pharmacotherapy, many health care providers have a limited understanding of the biological, social, and environmental factors that contribute to symptomology. Without a clear understanding of these factors, health care providers may not be able to provide adequate patient education or coach patients on how to lessen the impact or manage these problem areas. To do so, it is necessary to fully explicate the chronobiological, environmental, social, and genetic contexts that may predispose and perpetuate bipolar disorder. Further, because mania is the distinguishing feature of bipolar disorder, it is noteworthy that sleep takes a central role in the dynamics at work in the disorder. Unfortunately, most nurses have no background in the biological importance of sleep, the measurement of sleep, or common sleep disorders that affect patients, regardless of age or health status. In particular, this discussion includes how and when chronobiology, the environment, social rhythms, genetics, and vulnerability affect sleep and ultimately produce the mood and behavior diagnostic of bipolar disorder.

To illustrate the interactive and iterative nature of these various factors and behaviors, a model has been constructed that provides a visual framework to clarify the dynamics and complexity of the process (see Figure 1). The components of the model include the four domains of chronobiology, environment, social environment, and vulnerabilities. These components act, react, and interact to set the stage for bipolar disorder. Jointly, they can serve to maintain and escalate bipolar disorder symptoms. The interpersonal skill set of the individual also plays a part in mood and behavior. Individuals with better communication skills and more coping abilities may be able to buffer the effects of the ecologic domains and those with poor interpersonal skills are likely to do far worse. The vacillation of mood and the problematic behaviors characteristic of bipolar disorder are filtered in both directions through these interpersonal skills and abilities. Between interpersonal skills and the symbol representing mood and behavior, there is a rebounding arrow. This arrow, both leading to and emanating from the component of mood and behavior, indicates that the contributing elements can affect mood and behavior as well as the converse. Mood and behavior can have an exacerbating or dampening effect on the dynamics of the four core ecologic domains. As commonly observed among bipolar disorder patients, social and environmental conditions typically deteriorate as mood becomes more labile and behavior becomes more deviant. Likewise, when mood and behavior are improved with medications, psychosocial interventions, and sleep hygiene interventions, the negative conditions within some domains can be managed, reversed, or improved. 


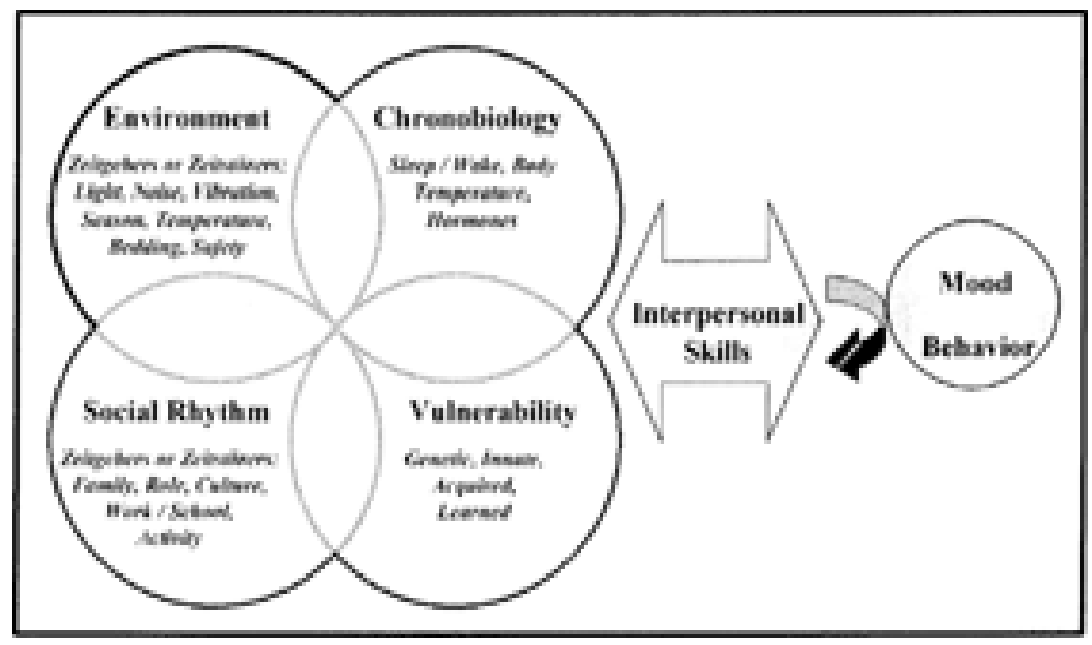

FIGURE 1 An ecological model of bipolar disorder.

The following discussion of sleep and the major domains of the model is not meant to be exhaustive, but it has been designed to identify the most salient and important aspects of how and when sleep disruption may play a part in the onset and exacerbation of bipolar disorder. A second aim of this paper is to introduce and reinforce the importance of prescribing, teaching, and reinforcing sleep hygiene practices among bipolar disorder patients. Although this runs countercurrent to our movement toward a 24-hour society, teaching patients to respect their bodies' own natural craving for the light/dark cycle may be as important as advocating medication adherence.

\section{CHRONOBIOLOGY AND SLEEP}

Chronobiology and sleep are central to understanding intrinsic biologic triggers and useful interventions for bipolar disorder. Although sleep is cyclical in nature it is also only one-half of the sleep/wake cycle. The natural rhythm of sleep and wake is one of many physical events that follow a circadian, or 24-hour, pattern. The interactions among light, body temperature, and the sleep/wake cycle are particularly important to understanding the relevance of chronobiology to bipolar disorder. Even though there are many other chronobiological influences, these two have been selected due to their relevance to bipolar disorder and the potential to modify their effects behaviorally.

\section{Light}

Like many other animals, human physiology and behavior has been shaped by the natural pattern of light and dark. Unlike rodents, humans prefer to be active under conditions of light. Until the discovery of the light bulb, humans were primarily active during the daytime when they could work, socialize, and procure food more easily and safely. Through evolution physiology adapted to light and dark patterns with cycles of their own. For example, melatonin plays an important role in sleep induction (Reiter, 2003). Melatonin, functionally linked to immune function and tumor inhibition, is excreted by the pineal gland in response to darkness. Specialized neurons on the retina initially transmit messages about light and darkness through the suprachiasmatic nuclei (SCN) whose neurons exhibit inherent circadian electrical rhythms and constitute the brain's biological clock or the central circadian pacemaker. The light message is then transmitted by preand post-ganglionic sympathetic neurons to the pineal gland (Küller, 2002). Although melatonin 
facilitates sleep onset and sleep maintenance, it is not soporific or hypnotic but acts on the circadian clock and also slightly reduces body temperature (Reiter, 2003). A complementary hormone to melatonin is cortisol, which acts as a mobilizer of physical and mental function in the human organism. In contrast to melatonin, this hormone dominates during high demands of daytime activity and plays a role in alertness (Rivest, Schultz, Lustenberger, \& Sizonenko, 1989).

Exposure to even very short durations of bright artificial light during normal periods of darkness prevents the excretion of normal amounts of melatonin and desynchronizes both the SCN and melatonin's normal circadian rhythm. That is, morning daylight serves as a zeitgeber or time cue to initiate a normal period of wakefulness. Conversely, bright light exposure at night serves as a zeitstorer or circadian rhythm disrupter for the same process. The degree of inhibition of melatonin and effect on the biological clock by mistimed light depends upon its wavelength, intensity, and the circadian phase at which the exposure occurs (Reiter, 2003). Resetting or entrainment of the circadian pacemaker also can occur deliberately as with traveling to a destination several time zones away. Although the body can accommodate to such changes, it does not do so without unpleasant physical effects that persist over several days, commonly known as jet lag. For example, shift work that requires frequent rotations between day and night work does not allow sufficient time to reset the biological clock in one direction or the other. The result is a more chronic form of jet lag that is physiologically stressful for even healthy individuals (Küller, 2002).

\section{Temperature}

In complement to the sleep/wake cycle, body temperature varies on a 24-hour basis and temperature decline is important to facilitate sleep onset. The normal pattern of core body temperature in healthy adults has a predictable sinusoidal rhythmic variability over each 24-hour period with a peak around 2100 hours and a minimum around 0500 hours. This pattern reflects heat generation in the morning hours and peripheral vasodilation for cooling during the night. However, under conditions without zeitgebers the intrinsic rhythm for body temperature is approximately 22.2 hours, which suggests that it must be regularly synchronized. Again, the $\mathrm{SCN}$ or circadian pacemaker acts in this capacity. Experimental testing has shown that sleep onset latency decreases rapidly as core body temperature declines and is shortest when core body temperature is lowest. Conversely, arousal (spontaneous awakening) was consistently observed to occur after body temperature began to rise from its nadir. Thus, even though other circadian and homeostatic processes are involved, both sleep propensity and sleep duration are influenced by the circadian phase of body temperature (Gilbert, van den Heuvel, Ferguson, \& Dawson, 2004). In addition, the old saying about taking a warm bath at bedtime to promote sleep has been tested empirically and found effective. The increased body warming caused by a bath creates rebound peripheral vasodilatation and rapid body cooling afterward, an event that enhances both sleep onset and quality of sleep (Kanda, Tochihara, \& Ohnaka, 1999). Conversely, exercise just before bedtime or in lieu of sleep during mania will elevate core body temperature and will make sleep onset more difficult.

\section{THE BASICS OF SLEEP}

Just like hunger, sleep is a normal physiological drive. The peaceful nature of sleep belies the cyclical, biochemical, and neurological complexity of sleep, which is still not fully understood. 
The gold standard for measuring and observing sleep is the use of polysomnography. This technique uses multiple instruments such as oxymetry, EMG, EKG, and EEG to track

physiological changes in the body simultaneously. Using this data the process or stages of sleep can be quantified over an entire night. Normal sleep occurs in a multi-cycle fashion where light sleep progresses to deeper sleep and is followed by rapid eye movement (REM) sleep in recurrent 90-minute cycles. Light sleep (Stage I and Stage II) is characterized by alpha waves on EEG and the deeper stages (Stage III and Stage IV) are identified by delta waves, also referred to as slow-wave sleep. This slow wave sleep is qualitatively different from the lighter stages of sleep. It is considered the "restorative" period of sleep and is important as a period of growth hormone secretion. These sequential stages of sleep are characterized by regular heart and respiratory rates, and diminished muscle tone without any dreaming. In contrast, REM sleep is a highly active brain state where dreaming occurs and includes rapid irregular respiratory and heart rates, diminished muscle tone, and characteristic rapid eye movements (Carskadon \& Dement, 2000).

The average person needs about 7-8 hours of sleep but everyone has their own particular sleep need (Ferrara \& De Gennaro, 2001). If undisturbed, repeated cycles of all sleep stages, from Stages I through IV followed by REM, will become progressively shorter over the rest of the sleep interval yielding 5-6 individual cycles with progressively longer REM periods. Thus, all sleep is not equal in quantity or importance. Further, if there is insufficient time allotted for sleep, the individual will suffer greatly reduced time in deep sleep and REM in part because these stages are longer in the latter half of the normal sleep interval (Carskadon \& Dement, 2000).

The result of sleep disruption or insufficient sleep reduces the amount of slow wave and REM sleep, which is linked to many common-acute and chronic physical and mental complaints (see Figure 2). Thus, it is apparent that neither sleep disturbance nor reduced sleep is a benign condition, even in healthy individuals. The Impaired Sleep illustration shows that the factors that can influence the human chronobiology are not isolated within the body. Social factors and external environments also can have major effects on the timing, quantity, and quality of sleep. The effects of sleep curtailment and sleep fragmentation include a myriad of physiologic, emotional, cognitive, behavioral, and social problems (Lee et al., 2004). However, in bipolar disorder, sleep loss has been identified as a potent trigger for mania (Barbini, Bertelli, Colombo, \& Smeraldi; 1996, Jackson, Cavanagh, \& Scott, 2003; Wehr, 1989; Wehr, Turner, Shimada, Lowe, Barker, \& Leibenluft, 1998). Other investigators have noted that new onset mania is especially common among women in the postpartum period when extended sleep loss is predictably unavoidable in new mothers (Sharma, 2003; Strouse, Szuba, \& Baxter, 1992).

\title{
FIGURE 2 IS OMITTED FROM THIS FORMATTED DOCUMENT
}

\author{
EFFECT OF ENVIRONMENT ON SLEEP \\ Ambient Light \\ Environmental factors may function as either zeitgebers or zeitstorers. These same conditions \\ that reinforce the normal biological rhythms can be a source of sleep disruption. For example, \\ permanent night shift workers typically struggle to establish and maintain a functional circadian \\ rhythm that promotes optimal alertness during working hours. Because these workers must
}


function in opposition to the natural dark/light cycle, they struggle with trying to sleep in spite of the intrusiveness of natural light exposure (Küller, 2002). Exposure to bright light, whether natural or artificial, has the same effect; it promotes alertness and reduces the natural processes that promote sleep. The "misuse" of bright artificial light at night is often referred to as a "drug" because of its effect on reducing melanin synthesis (Reiter, 2003). Thus, indiscriminate or habitual exposure to this drug during normal hours of darkness and sleep not only reduces melatonin but also disturbs its normal circadian rhythm.

As an example of the therapeutic power of the light/dark cycle, Wehr and colleagues used an intervention consisting of a 24-hour routine that included 14 hours of extended bed rest in complete darkness for a bipolar disorder patient with a long history of rapid cycling. This particular subject had been monitored continuously for several years using actigraphy and daily recordings of mood using a visual analogue scale. Although he had been under treatment and taking his medications as prescribed for several years, his symptoms were essentially uncontrolled. Shortly after beginning this strict routine (months), this cooperative subject stabilized dramatically. Thereafter, he had only subtle mood cycling (6-7 week cycles) in the euthymic range and his sleep was consolidated to within a 10-hour period of darkness (Wehr et al., 1998).

\section{Safety}

It is known that bipolar disorder has been associated with many negative social and economic consequences. As often happens with chronic bipolar disorder, the patient's living situation declines with progression of the disease (Calabrese et al., 2003). As a result, the quality of that person's sleeping environment would probably decline also. Consider for a moment the person with bipolar disorder who is institutionalized, incarcerated, living in a shelter, or homeless. Normally, safety is an assumed requisite for sleep and rest. Safety is more predictable when in a home environment, while sustained vigilance is required when safety is a concern (Thomas, Shattell, \& Martin, 2002). Persons with bipolar disorder who sleep in crowded or unsafe environments cannot be expected to obtain sufficient restful sleep.

\section{SOCIAL RHYTHMS AND SLEEP}

\section{Social Zeitgebers}

Activities that are socially and developmentally shaped (e.g., school or work inside and outside the home) essentially form the framework for how humans pass each day. Primary social roles (e.g., spouse, parent, or child) also shape expectations for time investments. These activities and role expectations usually have compelling circadian routines that are either explicit (e.g., work and school), or implicit (e.g., family obligations). Separately and in combination, these social influences provide reinforcement and cues to keep the behavior of individuals within the expected circadian rhythm. Through the mutually occurring processes of physical and social evolution, the light/dark cycle has also shaped social forces. In complementary fashion, social rhythms reinforce the inherent circadian process of the body. For example, social routines include the timing of daily activity, eating, and sleeping. Although sleeping may not have the obvious social relevance of humans eating meals together or the activity component of work or school, the synchronizing of sleep times helps ensure a quiet and dark environment for other members of the household to sleep. In addition, these rhythmic social aspects of human life are 
apparently important in the development and maintenance of individual psychological well-being and emotional stability (Frank, Schwartz, \& Kupfer, 2000).

\section{Social Zeitstorers}

On the other hand, if bipolar disorder families share similar sleep anomalies as reported by Lauer and colleagues (1995), then additional forms of sleep disturbance might also be elicited and perpetuated in children by the resulting disruptive environment at night (Hammen, Gordon, Burge, Adrian, Jaenicke, \& Hiroto, 1987; Stoleru, Nottelmann, Belmont, \& Ronsaville, 1997). Further, when social expectations regarding work/school performance or family role expectations are not met, the deviant individual will incur significant stress on many fronts. In the case of poorly controlled bipolar disorder, the individual can become out of rhyme with his or her own social milieu. For example, Coryelle and colleagues (1993) found that, compared to control subjects, patients with mood disorders were significantly more likely to report the following: declines in job status and income; failure to marry; and deficits in interpersonal relationships, enjoyment of recreational activities, and overall contentment. Others have found that community-dwelling adults symptomatic of bipolar disorder had significant difficulties with work-related performance, social/leisure activities, and social/family interactions. Important differences in social consequences also were noted when comparing by gender. Women reported more disruption in social and family life, while more men reported being arrested, jailed, and convicted for crimes. As might be expected, these subjects also reported more classic somatic symptoms of stress such as anxiety, panic attacks, and migraine headaches (Calabrese et al., 2003).

\section{INDIVIDUAL VULNERABILITY \\ Genetics}

The old debate over nature versus nurture in bipolar disorder is now becoming enlightened by the recent advances made in genetics. Although many older studies have shown a predisposition in families to a range of affective disorders, conspicuous clustering of sleep abnormalities also have been documented in these families (Lauer, Schreiber, Holsboer, \& Krieg, 1995). Numerous chromosomes are now considered as candidate genes for bipolar disorder (Baron, 2002; Papadimitriou, Dikeos, \& Soldatos, 2003). Longitudinal observations of children with the deletion of the gene fragment 22q11.2 (also known as Velocardiofacial Syndrome, DiGeorge Syndrome, Shprintzen Syndrome, or CATCH 22) have documented the very high prevalence of bipolar disorder and schizophrenia emerging in young adulthood (Papolos et al., 1996; Vogels et al., 2002). Consistent with the range of physical and behavioral manifestations caused by this genetic anomaly, Kelsoe (2003) has surmised that the genetic penetrance in bipolar disorder is not $100 \%$. This means that the probability of developing a condition in the presence of the genetic state is not a certainty. Also, he asserts that the trait displays variable expressivity given the variety of related clinical presentations from identical or similar genetic deletions. Lastly, Kelso concludes that bipolar disorder is genetically heterogeneous, meaning that multiple genes are probably involved. Bipolar disorder is probably only one condition among a spectrum of several disorders distributed as follows: starting with the mildest and most common (i.e., unipolar disease); then less common but more severe (i.e., bipolar disorder II and bipolar disorder I); and ending with the least common but most severe (i.e., schizophrenia). In such genetic conditions, symptomatology is more severe due to the contribution of more genes; milder forms develop when fewer genes are inherited. This "dose-effect" explanation is consistent with 
observations regarding the clustering of affective disorders and sleep abnormalities in families (Lauer et al., 1995; Smoller \& Finn, 2003) and also challenges traditional views about the potency of nurture alone.

Due to this apparent genetic heterogeneity of bipolar disorder, others have proposed examining the genetic underpinnings of endophenotypes or common markers of bipolar disorder (Lenox, Gould, \& Manji, 2002). Among the most obvious endophenotypes for bipolar disorder are the following: response to sleep deprivation; response to psychostimulants; response to cholinergics; and the most promising feature of bipolar disorder, abnormal regulation of circadian rhythms (the sleep/wake cycle, hormonal rhythms, etc.). This last marker is an apparent good choice for two reasons. The first is that non-human models can be used in this line of research because all organisms have circadian cycles. The second is related to the efficacy of the drug lithium and because this drug has been shown to regulate circadian cycles in a wide variety of species, including humans.

\section{Innate or Acquired}

Perceived stress, regardless of the origin, has long been associated with insomnia and also with the chronic activation of the hypothalamic-pituitary-adrenal (HPA) axis causing increases in corticotropin-releasing hormone (CRH) and cortisol (Vgontzas et al., 2001). One important effect of these hormones is an alerting response that promotes wakefulness and inhibits sleep (Tsuchiyama, Uchimura, Sakamoto, Maeda, \& Kotorii, 1995). Conversely, sleep, especially slow wave sleep, in normal individuals has an inhibitory influence on CRH and cortisol (Vgontzas et al., 1999). Due in part to the ethics of studying patients during untreated mania, other investigators have been able to identify important differences in treated bipolar disorder patients by using $\mathrm{CRH}$ challenge testing. For example, lithium controlled bipolar disorder patients, who were in a pre-relapse state (within a 12-month follow-up window), had higher baseline and peak concentrations of corticotropin over normal control subjects (Vieta et al., 1999). Other investigators also have found that remitted and unremitted bipolar disorder patients showed higher cortisol responses than controls. These findings suggest that HPA dysfunction may be a trait abnormality. Further, the question is posed whether this dysfunction is a premorbid condition or arises as a consequence of the disorder - a biological scar (Watson, Gallagher, Ritchie, Ferrier, \& Young, 2004).

\section{SLEEP DISORDERS AND SLEEP LOSS}

There are many common and treatable sleep disorders such as: insomnia; restless leg syndrome (RLS); and obstructive sleep apnea (OSA). Each of them, by different mechanisms, also will disturb sleep. Frequent arousals caused by these problems prevent the natural progression into deep sleep and REM sleep and thus yield more time in Stage I or II sleep. As a result, anyone with these sleep disorders will report awakening unrefreshed and fatigued, even after a full night in bed. More so, bipolar disorder patients are more likely to suffer more consequences from chronic sleep disruption. Further, it is possible that an undiagnosed sleep disorder could be at the root of rapid cycling in some cases. Unfortunately, sleep disorders are likely to remain undiagnosed when health care providers are unaware or uninformed about their importance in caring for bipolar disorder patients.

\section{Insomnia}


The diagnosis of insomnia includes complaints of delayed sleep onset, premature waking after sleep onset, and/or very early arousals that result in a shortened total sleep time (Drake, Roehrs, \& Roth, 2003). Insomnia may be transient or chronic and the perception of sleep duration may not correspond to objective assessment. The frequent awakenings suggestive of insomnia also may be a conditioned arousal response due to environmental or behavioral cues. Although the use of hypnotics may produce temporary symptom relief, they affect sleep architecture and consequently may cause deterioration in the quality of sleep. Anxiety associated with emotional conflict, stress, recent loss, feeling insecure at night, or change in living arrangement also can produce insomnia. The general anxiety and conditioned arousal response at sleep onset associated with insomnia may prompt more frequent use of over-the-counter or illegal hypnotics and alcohol, a common, but inappropriate, home remedy for insomnia. Insomnia may be traced to organic, psychological, pharmacological, chronobiological, or behavioral causes, but it also has been associated with cardiovascular, respiratory, GI, renal, and painful musculoskeletal disorders. When insomnia can be traced to pain, such as with arthritis or fibromyalgia, pain management should be initiated to promote sleep onset and sleep maintenance. The etiology and duration of insomnia should be the primary determination of the treatment selected. For example, insomnia associated with a psychological origin, such as depression or anxiety, is best treated from that perspective. If insomnia is of recent onset, then short-term pharmacotherapy may be suitable for transient symptoms. If sleep is fragmented, but otherwise normal, then pharmacologic and behavioral strategies to consolidate sleep may be effective in helping to restore an uninterrupted sleep interval. When insomnia is "learned" and this maladaptation interferes with the initiation of sleep, behavioral interventions are most appropriate. The American Academy of Sleep Medicine has published a comprehensive review of nonpharmacologic treatments for chronic insomnia (Morin et al., 1999). Their findings indicate that $70-80 \%$ of patients benefit from behavioral therapies and that improvements in sleep are sustained for a minimum of six months after treatment.

\section{Restless Leg Syndrome}

RLS is a chronic disorder characterized by an almost irresistible urge to move the limbs, usually associated with disagreeable leg sensations that worsen during inactivity. A recent telephone survey showed a prevalence of 3\% of those aged 18-29 years, $10 \%$ in those $30-79$ and $19 \%$ of those 80 years and older in a community based sample (Phillips et al., 2000). These patients are very restless sleepers because of their leg discomfort at night. Typically these patients report that they can obtain some relief from repeatedly getting up and walking around. Not surprisingly, people who share a bed with a RLS sufferer also will have very fragmented sleep. This common condition can interfere with both initiating and maintaining sleep. As a secondary condition, RLS may be caused by iron deficiency anemia, uremia, neurological lesions, diabetes, Parkinson's disease, rheumatoid arthritis, and as side effects of several psychiatric drugs (e.g., tricyclic antidepressants, SSRIs, lithium, dopamine blockers, xanthines). Although RLS does not require overnight polysomnography to diagnose and initiate treatment, it does require that the health care provider be knowledgeable about various types of sleep disorders and to maintain an ongoing and thorough sleep history of the patient.

A similar disorder, periodic leg movement disorder (PLMD) (also known as nocturnal myoclonus) is observed as involuntary flexion of the leg and foot. Although this movement disorder is not as uncomfortable as RLS it produces significant sleep fragmentation. Diagnosis of 
PLMD does require polysomnography. Although the etiology and associated mechanisms of this chronic disorder are not well defined, these movements have been linked to metabolic, vascular, and neurologic causes. Dopaminergic drugs are the most effective agents for the treatment for both of RLS and PLMD. Other drugs, including opioids, benzodiazepines, anticonvulsants, adrenergics and iron supplementation, are used to treat this particular sleep disorder (Chesson et al., 1999).

\section{Obstructive Sleep Apnea}

Given the increasing prevalence of obesity in the US and the fact that many of the newer atypical antipsychotics tend to cause weight gain, patients with bipolar disorder are at additional risk for obesity. As might be expected, depressive recurrence is significant by higher among bipolar disorder patients who are obese (Fagiolini, Kupfer, Houck, Novick, \& Frank, 2003). Obesity is known to contribute to the development of obstructive sleep apnea (OSA). This is a serious, but treatable, condition in which the soft upper airway structures collapse during sleep. OSA causes numerous apnea events that cause intermittent hypoxia throughout the night. To restore upper airway patency the person must awaken sufficiently to reopen the airway. An official diagnosis of OSA can be made when apneas occur at a rate of $>5 /$ hour of sleep. However, it is not uncommon for patients with severe symptoms to experience more than one apnea per minute. Although polysomnography is needed to diagnose OSA, these patients typically have a history of snoring, gasping, daytime sleepiness, and impaired daytime functioning (American Academy of Sleep Medicine Task Force, 1999). When obesity is not a factor in the development of OSA, persons with crowded airways (enlarged tonsils, narrow upper dental arch with malocclusion) and a small lower jaw (retrothagnia) are predisposed to OSA. The multiple awakenings caused by OSA severely fragment sleep, which prevents deep sleep and REM sleep. In addition, results from the Sleep Heart Health Study have shown that OSA is associated with the development of hypertension and cardiovascular disease (Shahar et al., 2001). Thus, the prevention and treatment of obesity should be coupled with vigilance for the signs and symptoms of OSA in bipolar disorder patients.

\section{WHY SLEEP HYGIENE?}

The first line of defense against sleep disruption is a lifestyle that promotes and ensures adequate sleep and rest. Although there is a natural drive to sleep, a restful environment and good sleep habits play important parts in being able to obtain quality sleep. There are many facets to sleep hygiene and each element bears review and reinforcement over time. Regardless of health status,

the Sleep Hygiene Measures are just as important for the average person as they are for bipolar disorder patients. Secondarily, nurses in acute care settings must be able to identify sleep disorders among their patients. Sleep disorders are not just bothersome, they can complicate care and pose important risks if they are not managed or diagnosed. Developing individualized plans of care for patients must include both active treatment of known sleep disorders and incorporation of Sleep Hygiene Measures.

\section{Sleep Assessment}

A careful history should be taken that includes both the patient and family members. People who share living and sleeping spaces can provide important information about sleep behavior that the patient may not be able to convey such as snoring, apnea, breath holding, restless sleep, and continuous leg movements. 
For patients with a current diagnosis of a sleep disorder, documentation and continuation of ongoing treatments, such as continuous positive airway pressure (CPAP), should be maintained and reinforced by patient and family education.

\section{Nursing Strategies}

The following strategies can help nurses provide care to their patients:

- Management of medical conditions, psychological disorders, and/or symptoms that interfere with sleep such as depression, pain, hot flashes, anemia, or uremia

- Review and/or adjust medications that have interactions and/or side effects that include daytime drowsiness or sleep impairment

- Instruction in and/or nursing delivery of Sleep Hygiene Measures (see below) with continuous follow-up

- Medical referral for suspected conditions such as obstructive sleep apnea and restless leg syndrome

- Ongoing assessment of adherence to prescriptions for sleep hygiene, medications, and/or use of devices to support respiration during sleep

- Given that many of the newer atypical antipsychotics tend to cause weight gain, obesity may become an additional health risk. Thus, weight maintenance or weight reduction may be necessary for many patients. Prevention of conditions such as obstructive sleep apnea should include helping the patient develop lifestyle habits that include regular exercise and good nutrition.

\section{SLEEP HYGIENE MEASURES}

The following list of strategies is essentially generic for anyone. These techniques are based on the current understanding of sleep mechanisms. Thus, the admonishments against caffeine, heavy meals, and exercise before bedtime apply to young and old, healthy and unwell alike.

- Due to the inherent problems with daytime sleeping caused by bright light, normal daytime noise, and disturbances by other people, persons with bipolar disorder should avoid jobs that involve working overnight. Even under the best circumstances, daysleepers have extreme difficulty protecting their sleep time and maintaining a healthy routine on a day-to-day basis.

- Use the bed only for sleeping (or sex). Don't watch TV, drink coffee, or read the newspapers while in bed. This will help to condition the sleeper that the bed means sleep and will behaviorally facilitate the initiation of sleep.

- Develop consistent and rest promoting bedtime routines such as taking a warm bath, relaxing activities, and/or light reading for the last 20-30 minutes before turning out the lights. Avoid watching TV programs that are violent or upsetting before going to bed. Developing a bedtime routine helps to habituate sleepiness and promotes sleep onset.

- Maintain the same bedtime and wake up time every day - even on holidays and weekends. Maintaining a regular schedule for working, eating, playing, and sleeping simply reinforces natural biorhythms and reduces stress.

- Exposure to bright light is desirable upon awakening, but should be avoided just prior to bedtime. Bright light is an important natural cue to entrain various biorhythms and for 
triggering alertness and wakefulness in the brain. Natural sunlight is best but bright artificial light will have the same effect. CAUTION: Phototherapy, using light boxes that deliver very bright light (10-20,000 lux), should be avoided in bipolar disorder because this intense light can trigger mania or suicidal ideation (Kantor, Browne, Ravindran, \& Horn, 1991; Praschak-Rieder, Neumeister, Hesselmann, Willeit, Barnas, \& Kasper, 1997).

- When fully awakened from sleep, get up out of the bed, no matter what time it is. Even when sleep is curtailed by circumstances, shortening the sleep cycle for one night will only make going to sleep later that night easier. This technique also will aid persons with insomnia to keep all their sleep time consolidated into one block of time.

- If frequent wakening during the night troubles the sleeper, avoid checking the clock as a habitual behavior. Frequent time checks will heighten anxiety and make sleeping more difficult. Although an alarm clock may be necessary to have in the bedroom, turn the clock to face the wall.

- Avoid naps entirely during the day. Napping will work against going to sleep easily later that day. If absolutely necessary, limit naps to 10-15 minutes in duration.

- Sleep in a completely dark, cool, and quiet environment.

- Complete darkness is often difficult to achieve given all of the extra lighting used at night around homes and businesses. Heavy curtains or light blocking shades work well for room darkening. When changing window coverings is not feasible, the sleeper can wear the type of eye masks/shades that are often sold in travel stores.

- A cool sleeping environment promotes sleep onset and sleep maintenance because body temperature normally drops during the sleep interval. A warm sleeping environment or exercising in the 3-4 hours before bedtime will work against the body's natural temperature rhythm.

- If some noise is unavoidable in the sleeping environment, soft foam earplugs may be helpful. These devices are sold at hardware stores for hearing protection of construction workers. They are inexpensive and very useful to take on trips or when a noisy environment may be likely. Also, some people find that the quiet but continuous noise of a fan or "white noise machines" is helpful to block out sounds that are aggravating during sleep.

- When sleep onset insomnia is a problem during the first 20 minutes in bed, the best behavioral technique is to get out of bed. Go into another room, read, or do a quiet activity using dim lighting for a brief period until drowsy. Don't turn on the television or turn on bright lights in the room during this period. These techniques reinforce the behavioral conditioning dictum that the bed is for sleeping. Avoiding bright light will protect melatonin excretion that is important in sleep induction.

- Many people find that sleeping alone is more restful than sleeping with another person or even their pets. Restless or snoring bed partners and pets are an important source of sleep fragmentation. If pets or bed partners are a problem, changing from a shared bed to two singles or keeping pets out of the bed may be helpful. If a snoring bed partner is the problem, this person may have a treatable sleep disorder. A thorough sleep history may reveal these important clues to sleep problems in the household.

- Avoid the following: caffeine and nicotine after 12 noon daily; alcohol intake (> 3 drinks); large meals 2-3 hours before bedtime to avoid acid reflux; exercise 2-3 hours before bedtime; emotional upset or emotionally charged activities prior to bedtime. 


\section{FOR MORE INFORMATION ABOUT SLEEP}

National Institute of Health (NIH) - National Center of Sleep Disorders Research (NCSDR) You can receive the following sleep disorders publications from the National Heart Lung Blood Institute (NHBLI) Information Center

- Facts about Sleep Apnea

- Facts about Insomnia

- Sleep Apnea: Is Your Patient at Risk? (an excellent publication to give to your physician)

Contact Information: NIH—NCSDR Two Rockledge Center, Suite 100386701 Rockledge Drive MSC 7920 Bethesda, MD 20892-7920 (301) 251-1222

\section{Resources on the Internet}

- NIH-National Center of Sleep Disorders Research http://www.nhlbisupport.com/sleep/patpub/patpub-a.htm

- NIH - National Institute of Neurological Disorders and Stroke Brain Basics: Understanding Sleep http://www.ninds.nih.gov/health_and_medical/pubs/understanding sleep_brain_basic.htm

- Restless Legs FactSheet http://www.ninds.nih.gov/health_and_medical/disorders/restless_doc.htm

- National Sleep Foundation http://www.sleepfoundation.org/

- Restless Legs Syndrome Foundation http://www.rls.org/

\section{REFERENCES}

1. (1999) Sleep-related breathing disorders in adults: Recommendations for syndrome definition and measurement techniques in clinical research. Sleep 22:5, pp. 667-689. 2. (1994) Diagnostic and statistical manual of mental disorders () 4th ed., Author, Washington, DC

3. (2002) American Psychiatric Association practice guideline for the treatment of patients with bipolar disorder () 2nd ed., American Psychiatric Publishing, Arlington, VA 4. Barbini, B., Bertelli, S., Colombo, C. and Smeraldi, E. (1996) Sleep loss, a possible factor in augmenting manic episode. Psychiatry Research 65:2, pp. 121-125.

5. Baron, M. (2002) Manic-depression genes and the new millennium: Poised for discovery. Molecular Psychiatry 7:4 , pp. 342-358.

6. Boivin, D. (2000) Influence of sleep-wake and circadian rhythm disturbances in psychiatric disorders. Journal of Psychiatry and Neuroscience 25:5 , pp. 446-458.

7. Calabrese, J. R., Hirschfeld, R. M., Reed, M., Davies, M. A., Frye, M. A., Keck, P. E., Lewis, L., McElroy, S. L., McNulty, J. P. and Wagner, K. D. (2003) Impact of bipolar disorder on a U.S. community sample. Journal of Clinical Psychiatry 64:4 , pp. 425-432. 8. Carskadon, M. A. and Dement, W. C. Krygert, M. H., Roth, T. and Dement, W. C. (eds) (2000) Normal human sleep: An overview. Principles and practice of sleep medicine, pp. 1525. 3rd ed., W.B. Saunders, Philadelphia

9. Chesson, A. L., Wise, M., Davila, D., Johnson, S., Littner, M., Anderson, W. M., Hartse, K. and Rafecas, J. (1999) Practice parameters for the treatment of restless legs syndrome and periodic limb movement disorder. Sleep 22:7 , pp. 961-968. 
10. Coryell, W., Scheftner, W., Keller, M., Endicott, J., Maser, J. and Klerman, G. L. (1993) The enduring psychosocial consequences of mania and depression. American Journal of Psychiatry 150:5 , pp. 720-727.

11. Drake, C. L., Roehrs, T. and Roth, T. (2003) Insomnia causes, consequences, and therapeutics: An overview. Depression and Anxiety 18:4 , pp. 163-176.

12. Fagiolini, A., Kupfer, D., Houck, P., Novick, D. and Frank, E. (2003) Obesity as a correlate of outcome in patients with bipolar I disorder. American Journal of Psychiatry 160:1, pp. 112-127.

13. Ferrara, M. and De Gennaro, L. (2001) How much sleep do we need?. Sleep Medicine Reviews 5:2, pp. 155-179.

14. Frank, E., Hlastala, S., Ritenour, A., Houck, P., Tu, X. M., Monk, T. H., Mallinger, A. G. and Kupfer, D. J. (1997) Inducing lifestyle regularity in recovering bipolar disorder patients: Results from the maintenance therapies in bipolar disorder protocol. Biological Psychiatry 41 , pp. 1165-1173.

15. Frank, E., Swartz, H. and Kupfer, D. (2000) Interpersonal and social rhythm therapy: Managing the chaos of bipolar disorder. Biological Psychiatry 48, pp. 593-604.

16. Gilbert, S. S., Heuvel, C. J. van den, Ferguson, S. A. and Dawson, D. (2004)

Thermoregulation as a sleep signaling system. Sleep Medicine Reviews 8:2 , p. 81.

17. Hammen, C., Gordon, D., Burge, D., Adrian, C., Jaenicke, C. and Hiroto, D. (1987)

Maternal affective disorders, illness, and stress: Risk for children's psychopathology.

American Journal of Psychiatry 144:6, pp. 736-741.

18. Jackson, A., Cavanagh, J. and Scott, J. (2003) A systematic review of manic and depressive prodromes. Journal of Affective Disorders 74:3 , pp. 209-217.

19. Kanda, K., Tochihara, Y. and Ohnaka, T. (1999) Bathing before sleep in the young and in the elderly. European Journal of Applied Physiology and Occupational Physiology 80:2 , pp. 71-75.

20. Kantor, D. A., Browne, M., Ravindran, A. and Horn, E. (1991) Manic-like response to phototherapy. Canadian Journal of Psychiatry 36:9 , pp. 697-698.

21. Kelsoe, J. (2003) Arguments for the genetic basis of the bipolar spectrum. Journal of Affective Disorders 71:1-2, pp. 183-197.

22. Küller, R. (2002) The influence of light on circarhythms in humans. American Journal of Medical Genetics 114:4, pp. 391-406.

23. Lauer, C. J., Schreiber, W., Holsboer, F. and Krieg, J. C. (1995) In quest of identifying vulnerability markers for psychiatric disorders by all-night polysomnography. Archives of General Psychiatry 52:2, pp. 145-153.

24. Lee, K. A., Landis, C., Chasens, E. R., Dowling, G., Merritt, S., Parker, K., Redeker, N., Richards, K. C., Rogers, A. E., Shaver, J. F., Umlauf, M. G. and Weaver, T. E. (2004) Learning objectives for sleep and chronobiology in undergraduate and graduate nursing education. Nursing Outlook 52:3, pp. 126-133.

25. Leibenluft, E. and Suppes, T. (1999) Treating bipolar illness: Focus on treatment algorithms and management of the sleep-wake cycle. American Journal of Psychiatry 156:12 , pp. 1976-1981.

26. Leibenluft, E., Albert, P., Rosenthal, N. and Wehr, T. (1996) Relationship between sleep and mood in patients with rapid-cycling bipolar disorder. Psychiatry Research 63:2-3, pp. 161-168. 
27. Lenox, R., Gould, T. and Manji, H. (2002) Endophenotypes in bipolar disorder. American Journal of Medical Genetics 114:4 , pp. 391-406.

28. Lewis, F. (2004) Demystifying the disease state: Understanding diagnosis and treatment across the bipolar spectrum. Journal of the American Psychiatric Nurses Association 10:3, pp. S6-S15.

29. Miklowitz, D., Richards, J., George, E., Frank, E., Suddath, R., Powell, K. and Sacher, J. A. (2003) Integrated family and individual therapy for bipolar disorder: Results of a treatment development study. Journal of Clinical Psychiatry 64:2 , pp. 182-191.

30. Morin, C. M., Hauri, P. J., Espie, C. A., Spielman, A. J., Buysse, D. J. and Bootzin, R. R. (1999) Nonpharmacologic treatment of chronic insomnia. Sleep 22:8 , pp. 1134-1156. 31. (2000) One-year prevalence of depressive disorders among adults 18 and over in the U.S.: NIMH ECA prospective data. Population estimates based on U.S. Census estimated residential population age 18 and over on July 1, 1998. Bipolar disorder research at the National Institute of Mental Health, National Institutes of Health http://nimh.nih.ogv/publicat/bipolarresfact — Available:

http://nimh.nih.ogv/publicat/bipolarresfact. cfm, retrieved on October, 22, 2004

32. Papadimitriou, G., Dikeos, D. and Soldatos, C. (2003) Sleep disturbance in unipolar and bipolar depression: Relationship to psychiatric family history. Neuropsychobiology 48:3, pp. 131-135. 33. Papolos, D., Faedda, G., Veit, S., Goldberg, R., Morrow, B., Kucherlapati, R. and Shprintzen, R. J. (1996) Bipolar spectrum disorders in patients diagnosed with velocardio-facial syndrome: Does a hemizygous deletion of chromosome 22q11 result in bipolar affective disorder?. American Journal of Psychiatry 153:12 , pp. 1541-1547.

34. Phillips, B., Young, T., Finn, L., Asher, K., Hening, W. A. and Purvis, C. (2000) Epidemiology of restless legs symptoms in adults. Archives of Internal Medicine 160:14, pp. 2137-2141.

35. Praschak-Rieder, N., Neumeister, A., Hesselmann, B., Willeit, M., Barnas, C. and Kasper, S. (1997) Suicidal tendencies as a complication of light therapy for seasonal affective disorder: A report of three cases. Journal of Clinical Psychiatry 58:9, pp. 389-392. 36. Reiter, R. (2003) Melatonin: Clinical relevance. Brain Research: Brain Research Reviews 42:3, pp. 204-220.

37. Rivest, R. W., Schulz, P., Lustenberger, S. and Sizonenko, P. C. (1989) Differences between circadian and ultradian organization of cortisol and melatonin rhythms during activity and rest. Journal of Clinical Endocrinology and Metabolism 68:4, pp. 721-729. 38. Shahar, E., Whitney, C., Redline, S., Lee, E., Newman, A., Nieto, F Javier, O'Connor, G. T., Boland, L. L., Schwartz, J. E. and Samet, J. M. (2001) Sleep-disordered breathing and cardiovascular disease: Cross-sectional results of the Sleep Heart Health Study. American Journal of Respiratory \& Critical Care Medicine 163:1 , pp. 19-25.

39. Sharma, V. (2003) Role of sleep loss in the causation of puerperal psychosis. Medical Hypotheses 61:4 , pp. 477-481.

40. Shattell, M. and Keltner, N. (2004) The case for antipsychotics in bipolar disorder. Perspectives in Psychiatric Care 40:1, pp. 36-40.

41. Smoller, J. W. and Finn, C. T. (2003) Family, twin, and adoption studies of bipolar disorder. American Journal of Medical Genetics 123C:1 , pp. 48-58.

42. Stoleru, S., Nottelmann, E. D., Belmont, B. and Ronsaville, D. (1997) Sleep problems in children of affectively ill mothers. Journal of Child Psychology and Psychiatry 38:7 , pp. 831-841. 
43. Strouse, T., Szuba, M. and Baxter, L. (1992) Response to sleep deprivation in three women with postpartum psychosis. Journal of Clinical Psychiatry 53:6 , pp. 204-206.

44. Thomas, S., Shattell, M. and Martin, T. (2002) What's therapeutic about the therapeutic milieu?. Archives of Psychiatric Nursing 16:3 , pp. 99-107.

45. Tsuchiyama, Y., Uchimura, N., Sakamoto, T., Maeda, H. and Kotorii, T. (1995) Effects of hCRH on sleep and body temperature rhythms. Psychiatry and Clinical Neuroscience 49:5-6 , pp. 299-304.

46. Tugrul, K. (2003) The nurse's role in the assessment and treatment of bipolar disorder. Journal of the American Psychiatric Nurses Association 9:6, pp. 180-186.

47. Vgontzas, A. N., Bixler, E. O., Lin, H. M., Prolo, P., Mastorakos, G., Vela-Bueno, A., Kales, A. and Chrousos, G. P. (2001) Chronic insomnia is associated with nyctohemeral activation of the hypothalamic-pituitary-adrenal axis: Clinical implications. Journal of Clinical Endocrinology and Metabolism 86:8, pp. 3787-3794.

48. Vgontzas, A. N., Mastorakos, G., Bixler, E. O., Kales, A., Gold, P. W. and Chrousos, G. P. (1999) Sleep deprivation effects on the activity of the hypothalamic-pituitary-adrenal and growth axes: Potential clinical implications. Clinical Endocrinology (Oxford) 51:2, pp. 205-215.

49. Vieta, E., Martinez-De-Osaba, M. J., Colom, F., Martinez-Aran, A., Benabarre, A. and Gasto, C. (1999) Enhanced corticotropin response to corticotropin-releasing hormone as a predictor of mania in euthymic bipolar patients. Psychological Medicine 29:4, pp. 971-978. 50. Vogels, A., Verhoeven, W., Tuinier, S., DeVriendt, K., Swillen, A., Curfs, L. and Frijns, J. P. (2002) The psychopathological phenotype of velo-cardio-facial syndrome. Annals of Human Genetics 45:2, pp. 89-95.

51. Watson, S., Gallagher, P., Ritchie, J. C., Ferrier, I. N. and Young, A. H. (2004) Hypothalamic-pituitary-adrenal axis function in patients with bipolar disorder. British Journal of Psychiatry 184 , pp. 496-502.

52. Wehr, T. (1989) Sleep loss: A preventable cause of mania and other excited states. Journal of Clinical Psychiatry 50, pp. 8-16. — (suppl 12)

53. Wehr, T., Turner, E., Shimada, J., Lowe, C., Barker, C. and Leibenluft, E. (1998) Treatment of rapidly cycling bipolar patient by using extended bed rest and darkness to stabilize the timing and duration of sleep. Biological Psychiatry 43:11, pp. 822-828. 